\title{
PELATIHAN STARTING MOTOR Y/D MENGGUNAKAN PLC PENGAJAR TEKNIK OTOMASI INDUSTRI SMK MUHAMMADIYAH 1 KEPANJEN
}

\author{
Drs. Tresna Umar Syamsuri, MT¹ ; Drs, Abdul Manaf, MMT ${ }^{2}$; Harrij Mukti K., ST., MT $^{3}$, \\ Ruwah Joto, ST., MMT ${ }^{4}$, Sigi Syah Wibowo, B. Tech., MT ${ }^{5}$ \\ ${ }^{1,2,3,4,5}$ Prodi Teknik Listrik, Jurusan Teknik Elektro, Politeknik Negeri Malang Indonesia \\ ${ }^{1}$ tresna.umar@polinema.ac.id
}

\begin{abstract}
Abstrak - PLC training aimed at instructors of the Industrial Automation Engineering Skills Competency Program in Muhammadiyah 1 Kepanjen, can improve the skills and motivation of teachers and students to know and understand PLCs and improve skills in making/assembling PLC practice modules for the development of PLC practice subjects. In addition, it can also increase additional skills for PLC field teachers in accordance with the applicable curriculum in SMK Muhammadiyah 1 Kepanjen.
\end{abstract}

Kata kunci: Skills, PLC practice

\section{PENDAHULUAN}

\subsection{Latar Belakang}

Kondisi lingkungan di SMK Muhammadiyah 1 Kepanjen, khususnya Program Kompetensi Keahlian Teknik Otomasi Industri yang sedang mengembangkan modul praktek PLC guna mempersiapkan dan menambah jumlah modul praktek untuk anak didiknya khususnya siswa-siswa SMK Muhammadiyah 1 Kepanjen. Untuk saat ini yang keinginan untuk mengembangkan modul-modul praktek khususnya yang berkaitan dengan PLC kurang dapat perhatian para pengajar praktek, sehingga menghambat kemajuan praktek bagi siswa SMK Muhammadiyah 1 Kepanjen, apalagi khususnya dapat dirasakan oleh siswa kelas tiga yang menghadapi ujian kompetensi personel.

Di SMK Muhammadiyah 1 Kepanjen terdapat 12 pengajar pada program Kompetensi Keahlian Teknik Otomasi Industri dan sebagian besar merupakan pengajar praktek. Mereka berpendidikan S1 dari sarjana pendidikan dan yang S1 bidang teknik hanya sebagian. Berdasarkan keduakondisi di atas, yaitu kondisi lingkungan dan kondisi potensi sumber daya manusia para pengajar, maka dapat diambil suatu peluang untuk dapat melaksanakan pengabdian pada masyarakat. Pengabdian pada masyarakat tersebut berbentuk Pelatihan PLC untuk Pengajar Teknik Otomasi Industri SMK Muhammadiyah 1 Kepanjen, sehingga nantinya dapat menambah keterampilan para pengajar dalam pelajaran dan praktek PLC. Kemudian diharapkan mereka dapat berupaya untuk melaksanakan perbaikan sarana modul praktek di Program Kompetensi Keahlian Teknik Otomasi Industri SMK Muhammadiyah 1 Kepanjen, sehingga dapat melaksanakan praktek dan uji kompetensi sesuai kurikulum SMK yang berlaku.

\section{TINJAUAN PUSTAKA}

Materi PLC untuk Pengajar Program Kopetensi Keahlian Teknik Otomasi Industri SMK Muhammadiyah 1 Kepanjen merupakan modul bahan ajar praktikum yang mengoperasikan peralatan sesuai dengan identifikasi masing-masing fungsi dan pengoperasiannya. Diagram kerja dan sistim PLC harus dipahami berdasarkan standar praktis. Penggunaan atau pemasangan tegangan kerja PLC harus sesuai dengan spesifikasi mikrokontrol itu sendiri. Penggunaan PLC pada pelajaran praktek yang dilakukan oleh Pengajar Teknik Otomasi Industri SMK Muhammadiyah 1 Kepanjen, diharapkan dapat menguasai permasalah kontrol industri dan kontrol permintaan stick holder. Pelaporan yang dibuat diharapkan sesuai dengan format dan prosedur yang berlaku.

Untuk menentukan sistem pengajaran praktek PLC di Teknik Otomasi Industri SMK Muhammadiyah 1 Kepanjen, harus mengetahui modul penunjang apa yang sesuai dengan kurikulum yang berlaku dan SDM pengajar yang ada dulu, guna memenuhi sasaran yang tepat. Oleh karena itu dengan mengikuti pelatihan PLC diharapkan pengetahuan dan keterampilan praktek PLC untuk Pengajar Teknik Otomasi Industri SMK Muhammadiyah 1 Kepanjen dikemudian hari menjadikan SMK tersebut semakin maju memenuhi kurikulum yang berlaku.

Dengan materi Pelatihan PLC untuk Pengajar Teknik Otomasi Industri SMK Muhammadiyah 1 Kepanjen sangat cocok untuk penunjang pada era kurikulum SMK sekarang bukan lagi barang yang baru, melainkan sesuatu yang harus terpenuhi demi kemajuan dan pemenuhan kurikulum praktek di SMK Muhammadiyah 1 Kepanjen.

\subsection{PLC}

Programmable Logic Controller (PLC) adalah sebuah rangkaian elektronik yang dapat mengerjakan berbagai fungsi-fungsi kontrol pada level-level yang kompleks. PLC dapat diprogram, dikontrol, dan dioperasikan oleh operator yang tidak berpengalaman dalam mengoperasikan komputer. PLC umumnya digambarkan dengan garis dan peralatan pada suatu diagram ladder.

PLC sebenarnya adalah suatu sistem elektronika digital yang dirancang agar dapat mengendalikan mesin dengan proses mengimplementasikan fungsi nalar kendali sekuensial, operasi pewaktuan (timing), pencacahan (counting), dan aritmatika.

\subsection{Kehandalan PLC (Programmable Logic Controller)}


- Flexibility

- Perubahan implementasi dan koreksi error

- Harga yang rendah

- Jumlah kontak yang banyak

- Memonitor hasil

- Observasi visual

- Kecepatan operasi

- Metode bolean atau ladder

- Reliability

- Penyederhanaan pemesanan komponen

- Dokumentasi

- Keamanan

- Memudahkan perubahan dengan pemrograman ulang.

\subsection{Bagian-bagian PLC}

Central Processing Unit (CPU)

CPU merupakan bagian utama dan merupakan otak dari PLC. CPU ini berfungsi untuk melakukan komunikasi dengan PC atau Console, interkoneksi pada setiap bagian PLC, mengeksekusi programprogram, serta mengatur input dan ouput system.

\section{Memori}

Memori merupakan tempat penyimpan data sementara dan tempat menyimpan program yang harus dijalankan, dimana program tersebut merupakan hasil terjemahan dari ladder diagram yang dibuat oleh user. Sistem memori pada PLC juga mengarah pada teknologi flash memori.

Sistem memori dibagi dalam blok-blok dimana masing-masing blok memiliki fungsi sendiri-sendiri. Beberapa bagian dari memori digunakan untuk menyimpan status dari input dan output, sementara bagian memori yang lain digunakan untuk menyimpan variable yang digunakan pada program seperti nilai timer dan counter.

PLC memiliki suatu rutin kompleks yang digunakan untuk memastikan memori PLC tidak rusak. Hal ini dapat dilihat lewat lampu indikator pada PLC.

\subsection{Modul/Rangkaian Input}

Kemampuan suatu sistem otomatis tergantung pada kemampuan PLC dalam membaca sinyal dari berbagai piranti input, contoh sensor. Untuk mendeteksi suatu proses dibutuhkan sensor yang tepat untuk tiap-tiap kondisi. Sinyal input dapat berupa logika 0 dan 1 (ON dan OFF) ataupun analog.

\subsection{Rangkaian output PLC}

Suatu sistem otomatis tidak akan lengkap jika sistem tersebut tidak memiliki jalur output. Output sistem ini dapat berupa analog maupun digital. output analog digunakan untuk menghasilkan sinyal analog sedangkan output digital digunakan untuk menghubungkan dan memutuskan jalur, misalnya piranti output yang sering dipakai dalam PLC adalah motor, relai, selenoid, lampu, dan speaker.

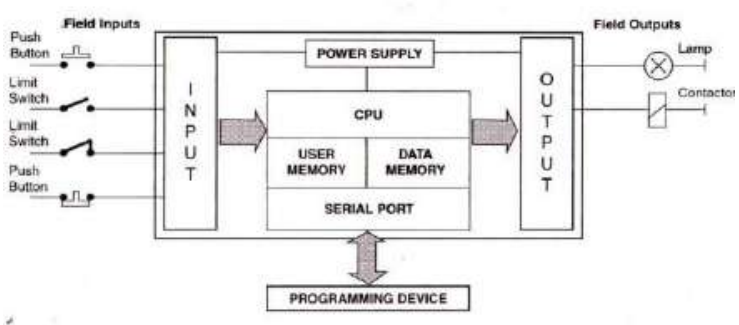

Gambar 2.1 Bagian-bagian PLC

Pemrograman Ladder (Diagram Tangga)

Diagram tangga merupakan metode pemrograman PLC yang paling sering digunakan. Instruksi dapat dibagi menjadi bagian masukan yang menyatakan kondisi dan keluaran yang akan dieksekusi apabila kondisi terpenuhi.

Diagram tangga menggunakan simbol standar untuk merepresentasikan elemen rangkaian dan fungsi dalam sistem kontrol. Diagram tangga terdiri dari dua garis vertikal. Antara kedua garis vertikal tersebut terdapat simbol-simbol switch contact normally open (NO), switch contact normally closed (NC), timer, counter, fungsi, dan keluaran (coil). Sebuah diagram tangga ditunjukkan dalam Gambar 2.2.

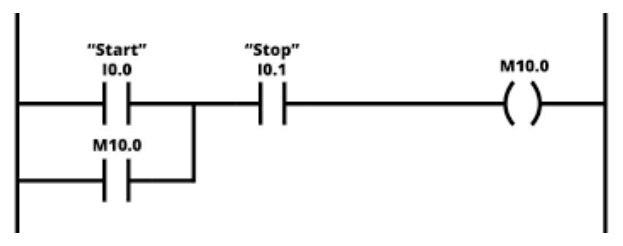

Gambar 2.2. Ladder diagram

Instruksi Dasar

Banyak kontrol yang mengharuskan dilakukannya tindakan-tindakan pengontrolan ketika suatu kombinasi dari kondisi-kondisi tertentu terpenuhi. Hal tersebut dapat digambarkan dengan sebuah persamaan atau gerbang-gerbang logika. Gerbang-gerbang logika yang biasa digunakan, antara lain:

a. Logika AND

Gerbang AND pada sebuah diagram tangga diperlihatkan pada Gambar 2.3. Untuk menghasilkan Output ON (logika 1) maka Input A dan Input B harus dalam keadaan ON.

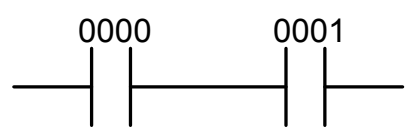

Gambar 2.3 Diagram Tangga untuk Logika AND

b. Logika OR

Sistem gerbang OR pada sebuah diagram tangga diperlihatkan pada Gambar 2.4. Untuk menghasilkan Output ON (logika 1) maka Input A atau Input B (atau keduanya) dalam keadaan $\mathrm{ON}$. 


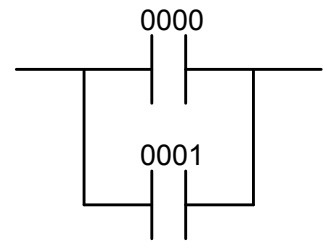

Gambar 2.4 Diagram Tangga untuk Logika OR

\section{c. Logika NOT}

Sistem gerbang NOT pada sebuah diagram tangga diperlihatkan pada Gambar 2.5. Output akan bernilai ON justru jika input A sedang tidak aktif (OFF atau logika 0). Masukan A disini dikatakan sebagai kontak normally closed (NC).

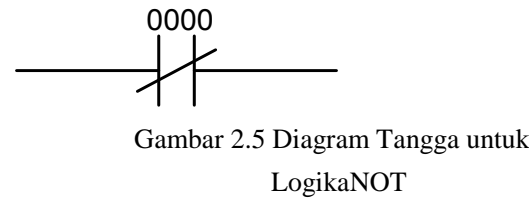

\section{d. Logika NAND}

Gambar 2.6 memperlihatkan sebuah diagram tangga yang mengimplementasikan sebuah logika NAND.

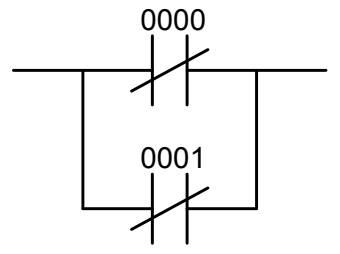

Gambar 2.6 Diagram Tangga untuk

$$
\text { Logika NAND }
$$

\section{e. Logika NOR}

Gambar 2.7 memperlihatkan sebuah diagram tangga yang mengimplementasikan sebuah logika NOR.

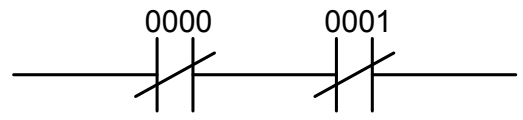

\section{Gambar 2.7 Diagram Tangga untuk}

Logika NOR

f. Logika XOR

Sebuah logika OR menghasilkan output ketika salah satu atau kedua inputnya berada dalam kondisi 1 . Akan tetapi, pada situasi-situasi tertentu, dibutuhkan sebuah logika yang dapat menghasilkan output ketika salah satu di antara kedua inputnya, tidak keduanya sekaligus, bernilai 1. Logika seperti ini disebut logika OR Eksklusif atau XOR. Salah satu cara untuk mendapatkan logika semacam ini adalah dengan meng-gabungkan logika-logika NOT, AND, dan OR seperti Gambar 2.8.

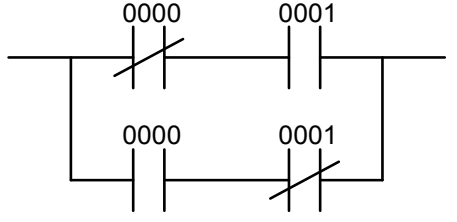

Gambar 2.8 Diagram Tangga untuk Logika XOR

g. Timer

Timer adalah sebuah perintah penghitungan waktu, metode umum dari pemrograman sebuah rangkaian timer adalah untuk menentukan interval yang dihitung dari suatu kondisi atau keadaan. Cara kerja dari instruksi Timer adalah, ketika Timer mendapatkan input selama set value akan mengaktifkan contact-contactnya.
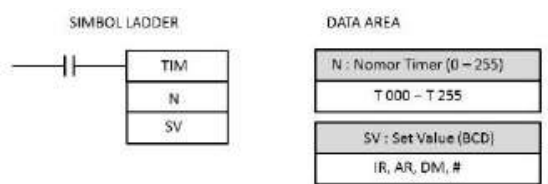

Gambar 2.9. Pengaturan Instruksi Timer

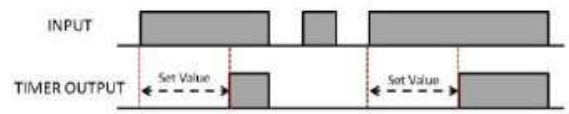

Gambar 2.10. Diagram Waktu Timer

\subsection{Motor AC Tiga Fasa}

Motor listrik 3 fasa adalah motor yang bekerja dengan memanfaatkan perbedaan fasa pada sumber untuk menimbulkan gaya putar pada bagian rotornya. Perbedaan fasa pada motor 3 phase didapat langsung dari sumber. Hal tersebut yang menjadi pembeda antara motor 1 fasa dengan motor 3 fasa.

Secara umum, motor 3 fasa memiliki dua bagian pokok, yakni stator dan rotor. Bagian tersebut dipisahkan oleh celah udara yang sempit atau yang biasa disebut dengan air gap. Jarak antara stator dan rotor yang terpisah oleh air gap sekitar 0,4 milimeter sampai 4 milimeter.

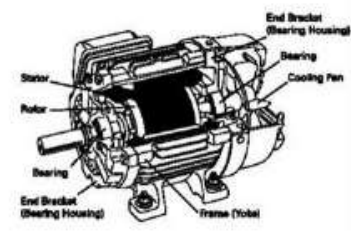

Gambar 2.11. Penampang motor sangkar

Prinsip kerja dari motor listrik 3 fasa ini sebenarnya sangat sederhana. Bila sumber tegangan 3 fase dialirkan pada kumparan stator, maka akan timbul medan putar dengan kecepatan tertentu. Besarnya kecepatan tersebut dapat diukur menggunakan sebuah rumus Ns $=120 \mathbf{f} / \mathbf{P}$. Dimana Ns adalah kecepatan putar, $\mathrm{f}$ adalah frekwensi sumber, dan $\mathrm{P}$ adalah kutub motor.

Perlu diketahui bahwa medan putar stator akan memotong batang konduktor yang ada pada rotor, 
sehingga pada batang konduktor dari rotor akan muncul GGL induksi. GGL akan menghasilkan arus (I) serta gaya (F) pada rotor. Agar GGL induksi timbul, diperlukan perbedaan antara kecepatan medan putar yang ada pada stator (ns) dengan kecepatan berputar yang ada pada rotor (nr).

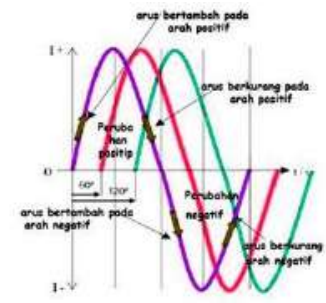

Gambar 2.12. Medan putar stator

Perbedaan kecepatan antara stator dan rotor disebut slip (s) yang dapat dinyatakan dengan rumus $\mathbf{s}=(\mathbf{n s}-\mathbf{n r}) / \mathbf{n s}$. Apabila $\mathrm{nr}=\mathrm{ns}$, maka GGL induksi tidak akan timbul, dan arus tidak akan mengalir pada batang konduktor (rotor), dengan demikian tidak dihasilkan kopel. Berdasarkan cara kerja tersebut, motor 3 fasa juga dapat disebut sebagai motor tak serempak atau motor asinkron.

Berikut adalah kelebihan dan kekurangan dari motor listrik 3 fasa:

\section{Kelebihan}

Konstruksi motor terbilang sangat kuat dan sederhana tinggi

Harga motor relatif murah dengan ketahanan

Effesiensi relatif tinggi pada saat keadaan normal

Biaya pemeliharaan relatif rendah

\section{Kekurangan}

Kecepatan sulit dikontrol

Arus start besar, yakni 5 sampai 7 kali dari arus nominal

Power faktor yang rendah pada beban ringan

\section{Hubungan Y/D}

Pengasutan/proses starting dari sebuah motor listrik tiga fasa menarik arus yang tinggi. Arus starting ini bisa mencapai 4 sampai 7 kali arus nominal dari motor ini. Ada banyak teknik untuk memperkecil arus starting ini, ssalah satunya dengan metoda star delta (Y/D).

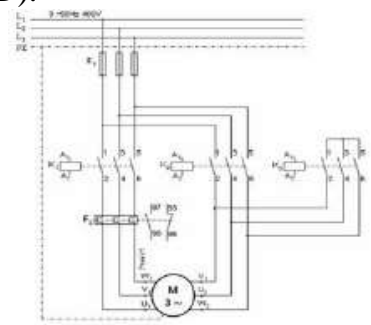

Gambar 2.13. Rangkaian Starting Y/D

Sudah disebutkan bahwa arus starting motor listrik biasanya sekitar empat hingga tujuh kali lebih besar dari arus nominalnya. Ini disebabkan motor listrik membutuhkan torsi awal yang besar agar dapat melawan inersianya dan inersia bebannya dari keadaan diam.

Torsi motor adalah proporsional dengan kuadrat fluks. Fluks adalah perbandingan tegangan dan frekuensi. Tegangan memiliki hubungan sebanding dengan arus. Pada akhirnya, torsi besar berarti akan membutuhkan konsumsi arus yang besar juga, berikut adalah pembuktian singkat bahwa arus starting stardelta lebih kecil daripada saat DOL.

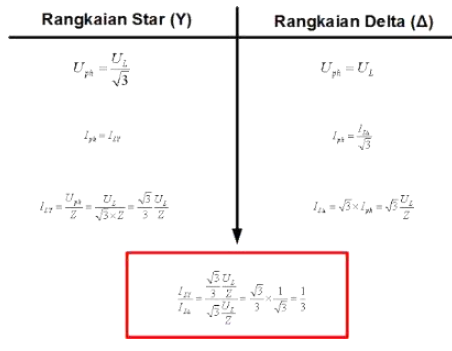

Gambar 2.14. Perbandingan Motor Y/D

\section{MATERI DAN METODE}

\subsection{Khalayak Sasaran}

Pelatihan ini ditujukan untuk kepada pengajar Teknik Otomasi Industri SMK Muhammadiyah 1 Kepanjen.

\subsection{Metode PKM}

Untuk menentukan metode PKM maka sistem pengajaran praktek di program pengabdian masyarakat ini, telah diketahui modul penunjang apa yang sesuai dengan kurikulum yang berlaku dan SDM pengajar yang ada, guna memenuhi sasaran yang tepat. Oleh karena itu dengan pengetahuan dan keterampilan cara merancang, merencanakan modul praktek Starting motor Y/D menggunakan PLC untuk Pengajar Teknik Otomasi Industri SMK Muhammadiyah 1 Kepanjen. Dengan diadakan pelatihan ini diharapkan guru praktek di lingkungan Teknik Otomasi Industri SMK Muhammadiyah 1 Kepanjen termotivasi untuk membuat modul praktek Starting motor Y/D menggunakan PLC yang baru, demi kemajuan dan pemenuhan kebutuhan masya-rakat stick holder mengenai penggunaan modul Starting motor Y/D menggunakan PLC yang beraneka ragam.

Kegiatan pelatihan Starting motor Y/D menggunakan PLC ini, dilaksanakan dengan metode langsung praktek, yaitu:

- Pengenalan PLC

- Pengenalan Motor 3 fasa

- Pengoperasian macam-macam modul praktek motor 3 fasa.

- Metode ini dipilih karena mengingat keterbatasan waktu, tenaga, dan dana yang tersedia.

\subsection{Rancangan Evaluasi}

Evaluasi diadakan pada hari kedua, yaitu di akhir acara, meliputi: 
Demontrasi, presentasi dan wawancara langsung terhadap peserta pelatihan.

Praktek pengoperasian modul-modul PLC dan motor 3 fasa, disamping itu untuk melihat secara nyata, hasil ketrampilan yang telah diajarkan kepada pengajar Teknik Otomasi Industri SMK Muhammadiyah 1 Kepanjen. Secara keseluruhan, akan dilakukan peninjauan langsung oleh tim pelaksana 15 hari kemudian.

\section{HASIL DAN PEMBAHASAN}

Berdasarkan metode yang diterapkan dalam pelaksanaan pengabdian kepada masyarakat ini, maka dapat dicapai hasil antara lain:

1. Metode, materi dan peragaan jika dikaitkan dengan keterbatasan waktu pelaksanaan yang dilaksanakan dapat efektif mencapai tujuan yang diinginkan oleh Peserta Pelatihan Starting Motor Y/D Menggunakan PLC Pengajar Teknik Otomasi Industri SMK Muhammadiyah 1 Kepanjen Kabupaten Malang dan dapat melihat langsung modul dipasang.

2. Peserta pelatihan dapat terampil melakukan Pelatihan Starting Motor Y/D Menggunakan PLC secara sederhana dengan baik dan standart.

3. Peserta pelatihan dapat mengatasi sendiri, jika ada permasalahan atau kerusakan pada modul praktek Starting Motor Y/D Menggunakan PLC.

4. Peserta dapat menikmati secara langsung hasil dari pelatihan Starting Motor Y/D Menggunakan PLC.

\section{SIMPULAN DAN SARAN}

\subsection{Kesimpulan}

Setelah menelaah segala sesuatu yang berhubungan dengan aktivitas Pelatihan Starting Motor Y/D Menggunakan PLC untuk Pengajar Teknik Otomasi Industri SMK Muhammadiyah 1 Kepanjen Kabupaten Malang, maka dapat diambil kesimpulan yaitu:

1. Membantu dan memberikan tambahan ketrampilan peserta Pelatihan Starting Motor Y/D Menggunakan PLC.

2. Memotivasi para peserta pelatihan yaitu pengajar dan siswa, untuk pengembangan modul praktek Starting Motor Y/D Menggunakan PLC yang ada di program studi.

3. Memperbanyak keterampilan Pengajar Teknik Otomasi Industri SMK Muhammadiyah 1 Kepanjen Kabupaten Malang, hal tersebut dapat dilihat dari antusias yang tinggi dari peserta pelatihan dan mereka mengharapkan adanya tindak lanjut program pengabdian kepada masyarakat berikutnya.

\subsection{Saran}

Perlu adanya tindak lanjut dari kegiatan Pengabdian Kepada Masyarakat ini, terutama dalam memberikan bimbingan dan dorongan kepada peserta pelatihan tentang manfaat dari Pelatihan Starting Motor Y/D Menggunakan PLC.

\section{DAFTAR PUSTAKA}

[1]. Bolton, W, 2006, "Programmable Logic Controllers" Fourth Edition, Newnes is an imprint of Elsevier Linacre House, Jordan Hill, Oxford OX2 8DP 30 Corporate Drive, Suite 400, Burlington, MA 01803

[2]. Bryan, L. A. And Bryan, E. A. 1988, "Programmable Controllers Theory and Implementation", An Industrial Text Company Publication Atlanta, Georgia, USA.

[3]. David H. Sirait, 2008, “Analisis Starting Motor Induksi Tiga Phasa Pada PT. Berlian Unggas Sakti TJ', Morawa, USU RepositoryC 2009

[4]. E.A. Parr, MSc, CEng, MIEE, MinstMC, "Programmable Controllers An engineer's guide", Third edition, Newnes, An imprint of Elsevier Linacre House, Jordan Hill, Oxford OX2 8DP 200 Wheeler Road, Burlington, MA 01803

[5]. Grainger John J and Stevenson Jr. William D, 1994, "Power system analysis", McGraw-Hill, Inc., New York.

[6]. Hugh Jack, 2003, "Automating Manufacturing Systems with PLCs", (Version 4.2, April 3, 2003), jackh@gvsu.edu

[7]. Seifer, Marc J., 1998, "Wizard, the Life and Times of Nikola Tesla", ISBN (HC), ISBN (SC)

[8]. Sen, P.C., 1989, "Principles of Electric Machines and Power Electronics", John Wiley \& Son, New York.

[9]. Wijaya, Mochtar, S.T., 2001, “Dasar-Dasar Mesin Listrik”, Jakarta, Djambatan.

[10]......., 1999, "DL405, Installation and I/O Manual", Manual Number D4-INST-M, Koyo Electronics Industries Co., LTD. 